Article

\title{
Temperature Distribution in Insulated Temperature-Controlled Container by Numerical Simulation
}

\author{
Bin $\mathrm{Li}^{1}$, Jiaming Guo ${ }^{1}$, Jingjing Xia ${ }^{1,2}$, Xinyu Wei ${ }^{1}$, Hao Shen ${ }^{1}$, Yongfeng Cao ${ }^{1}$, Huazhong Lu ${ }^{3}$ \\ and Enli $L \ddot{u}^{1, *}$ \\ 1 College of Engineering, South China Agricultural University, Guangzhou 510642, China; \\ ganli180@sina.com (B.L.); jmguo@scau.edu.cn (J.G.); ligan11221@163.com (J.X.); wxyscau@163.com (X.W.); \\ sh1024384685@163.com (H.S.); 17864386076@163.com (Y.C.) \\ 2 Schools of Automobile, Guangdong Mechanical and Electronical College of Technology, \\ Guangzhou 510515, China \\ 3 Guangdong Academy of Agricultural Sciences, Guangzhou 510640, China; huazlu@scau.edu.cn \\ * Correspondence: enlilv@scau.edu.cn; Tel.: +86-020-8528-2860
}

Received: 7 August 2020; Accepted: 11 September 2020; Published: 12 September 2020

\begin{abstract}
Cold-storage containers are widely used in cold-chain logistics transportation due to their energy saving, environmental protection, and low operating cost. The uniformity of temperature distribution is significant in agricultural-product storage and transportation. This paper explored temperature distribution in the container by numerical simulation, which included ventilation velocity and the fan location. Numerical model/numerical simulation showed good agreement with experimental data in terms of temporal and spatial air temperature distribution. Results showed that the cooling rate improved as velocity increased, and temperature at 45 min was the lowest, when velocity was $16 \mathrm{~m} / \mathrm{s}$. Temperature-distribution uniformity in the compartment became worse with the increase in ventilation velocity, but its lowest temperature decreased with a velocity increase. With regard to fan energy consumption, the cooling rate of the cooling module, and temperature-field distribution in the product area, velocity of $12 \mathrm{~m} / \mathrm{s}$ was best. Temperature standard deviation and nonuniformity coefficient in the container were 0.87 and 2.1 , respectively, when fans were located in the top four corners of the container. Compared with before, the average temperature in the box was decreased by $0.12{ }^{\circ} \mathrm{C}$, and the inhomogeneity coefficient decreased by more than twofold. The results of this paper provide a better understanding of temperature distribution in cold-storage containers, which helps to optimize their structure and parameters.
\end{abstract}

Keywords: computational fluid dynamics; numerical analysis; cold-storage container; temperature distribution; optimization; cold chain

\section{Introduction}

The development of cold-chain transportation was facilitated by population growth and the increasing demand of consumers for fresh food [1]. Refrigerated trucks are an important link of food transportation, and the most common mode of transportation in a cold chain $[2,3]$.

At present, diesel-engine-driven mechanical steam-compression refrigeration is still the main technology of cold-chain land transportation [4]. This kind of refrigeration has high noise, maintenance costs, and $\mathrm{CO}_{2}$ emissions, and its efficiency is only 35-40\% [5], causing such refrigerated vehicles confronted with restrictions when they deliver in large cities [1]. Phase-change materials (PCMs) can change their physical state over a range of temperatures, releasing and storing large amounts of energy during melting or solidification, thus changing the temperature of the surrounding environment [6-9]. 
They are widely used in various cold-storage and cold-transportation systems [10-15]. Due to their energy-saving, environmental protection, and low operating cost advantages, refrigerated storage vehicles are increasingly favored by transport operators $[4,16]$. Cold-storage vehicles mainly release their cold quantity through natural and forced convection $[4,16-18]$. Both cooling methods are subject to local supercooling and poor temperature uniformity in the container.

A number of studies showed that the uneven distribution of refrigerating capacity in refrigerated containers still poses significant challenges to product freshness and quality in long-distance transportation and harsh environments [19-22]. Reasonable temperature distribution can ensure the even distribution of the cooling capacity, save energy consumption, reduce dry consumption and freeze-damage loss, and improve the quality of fresh fruit [23]. Therefore, it is necessary to improve the distribution of the cooling capacity of fruit transport equipment. In general, temperature uniformity mainly depends on the external environment and internal air circulation [24]. The most direct way to reduce the influence of external ambient temperature fluctuations on internal temperature is to improve container insulation performance. Many scholars proposed to replace part of the polyurethane foam with a vacuum heat shield with a lower heat-transfer coefficient [25-27] to improve the insulation of the vessel and the utilization rate of the internal space. The main factors affecting internal air circulation are the design of refrigerated containers, the perforation rate of cargo packaging, the way in which packages are stacked, and pallet configuration [20]. However, it is very time-consuming and laborious to obtain an optimal parametric solution of internal air-flow optimization by experiment.

Computational fluid dynamics (CFD) modeling is an alternative to expensive and cumbersome experiments, and the primary method for analyzing flow and temperature fields in fruit storage and transportation [28,29]. Many studies modeling air-flow patterns and temperature distribution in refrigeration rooms demonstrated the appropriateness of this approach. The authors in [30] used numerical simulation and experiment methods to study the influence of the presence or absence of a supply air-duct system for ventilation performance and temperature uniformity in the container. Results showed that the air-duct system could improve overall ventilation uniformity in the container and reduce cargo temperature difference. In order to reduce the loss of cold air flow, the authors in [20] added three diversion plates to the refrigerated container to prevent air flow from passing through the air gap. Compared with before the improvement, temperature distribution was within $\pm 1{ }^{\circ} \mathrm{C}$, and cooling time was also reduced by at least $22.9 \%$. Kayansayan et al. [31] numerically analyzed the conjugate heat transfer in the refrigerated container, and the effects of the container shape, inlet channel width, and Reynolds number of cold air on temperature distribution. Jara et al. [32] used a CFD shear-stress transfer calculation model to simulate temperature distribution in a specific refrigerator vehicle, and studied the refrigeration cycle in the cold space of the vehicle at a lower cost. Han et al. [33] used 3D CFD models to simulate air flow and heat transfer under different unsteady-turbulence models, and predicted temporal and spatial temperature and velocity changes during cooling. In terms of the application of cold storage, Yang et al. [34] verified the feasibility of combining cold storage with latent heat storage by using a CFD model, and carried out a simulation analysis on the temperature-distribution and heat-transfer characteristics of cold storage. In addition, Xie et al. [35] analyzed the influence of different cold-plate layouts on the temperature-field distribution in no-load refrigerated vehicles by using computational fluid dynamics combined with experiment verification.

Previous studies on CFD modeling and simulations of refrigeration space lack research on the location of fans and air velocity inside the container, especially for storage refrigerators with limited cold-source cooling capacity. Air-flow velocity and distribution have great influence on the heat-exchange rate of the storage module and the cargo area, so it is necessary to study the location of the fan and air velocity inside the storage refrigerator.

This study revealed the temperature distribution in a container by a validated CFD model. Besides, the performance of four velocities and four locations of the fan were compared to explore the influence of operating parameters on temperature distribution. The results of this research provided reliable references of container optimization in the cold chain. 


\section{Materials and Methods}

\subsection{Materials}

Figure 1 shows the structures and product-stacking methods in the insulated temperature-controlled container (ITCC) developed by the College of Engineering, South China Agricultural University. The ITCC was $2 \mathrm{~m}$ long, $1.8 \mathrm{~m}$ wide, and $1.72 \mathrm{~m}$ tall. It consisted of a fresh-keeping area, cold-storage area, and internal circulation duct. After the fan is engaged, cool air is absorbed into the fresh-keeping area by the fans and exchanges heat with the products, which raises the air temperature and reduces the product temperature.

We used $25 \mathrm{~mm}$ thick vacuum insulation boards (VIPs) as the core insulation layer in the middle of ITCC walls, which were pasted with $30 \mathrm{~mm}$ polyurethane (PU) on both sides to strengthen them. Then, $2 \mathrm{~mm}$ glass-fiber-reinforced composite plastics (GFRP) were used as the inner and outer skin. The main properties of the materials are listed in Table 1.

Cold-storage plates were designed in two sizes for effective utilization of the cold storage: 12 plates sized $1 \mathrm{~m} \times 0.03 \mathrm{~m} \times 0.2 \mathrm{~m}$, and 24 plates sized $1 \mathrm{~m} \times 0.04 \mathrm{~m} \times 0.2 \mathrm{~m}$, containing 4 and $7 \mathrm{~kg}$ of PCMs of each plate, respectively. PCMs with a phase-change point of $-15^{\circ} \mathrm{C}$ and latent heat value of $339.2 \mathrm{~kJ} / \mathrm{kg}$ was used as the cold source. PCMs was produced by Guangzhou Hicool Technology Co., Ltd., Guangzhou, which is sodium nitrate dissolved in water with some additives. In this study, the fresh-keeping area was loaded with navel oranges packed in 30 cartons $0.48 \mathrm{~m}$ long, $0.32 \mathrm{~m}$ wide, and $0.25 \mathrm{~m}$ tall each. Each bin contained roughly $15 \mathrm{~kg}$ of oranges.

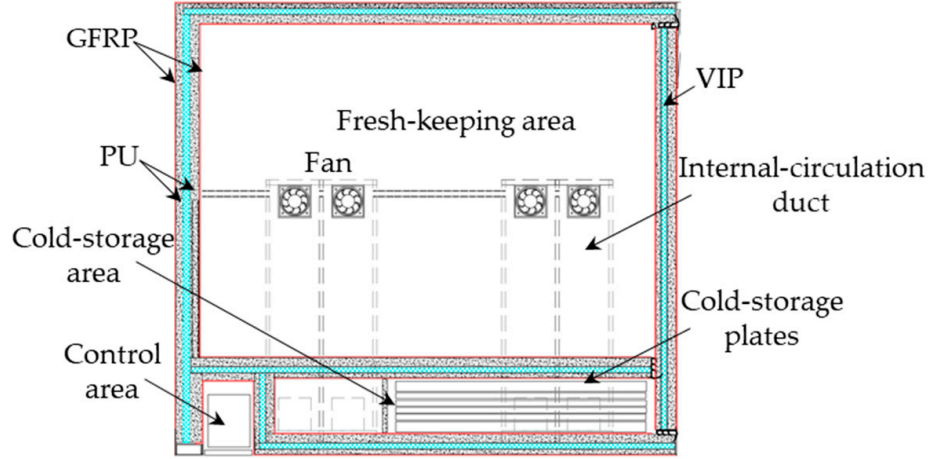

(a)

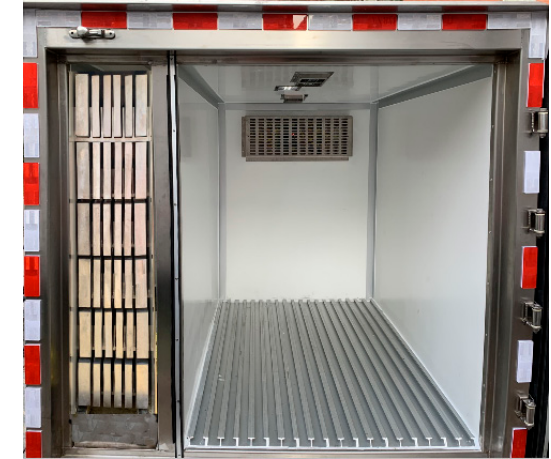

(b)

Figure 1. Structure of insulated temperature-controlled container (ITCC): (a) vertical view and (b) side elevation.

Table 1. ITCC material property parameters. VIP, vacuum insulation board; PU, polyurethane; GFRP, glass-fiber-reinforced composite plastics.

\begin{tabular}{ccc}
\hline Materials & Density $\left(\mathbf{k g} / \mathbf{m}^{\mathbf{3}}\right)$ & Thermal Conductivity $(\mathrm{W} /(\mathbf{m} \cdot \mathbf{K}))$ \\
\hline VIP & 280 & 0.0048 \\
PU & 45 & 0.0244 \\
GFRP & 1800 & 0.4651 \\
\hline
\end{tabular}

\subsection{Mathematical Model}

It is difficult to exactly simulate the entire flow-field environment, and the model used in this simulation was simplified $[30,36,37]$. The product zone was simplified to a porous medium. Some assumptions were adopted, which improved computational efficiency without affecting computational accuracy, namely, the air in the container was a Newtonian fluid and incompressible and it simultaneously conformed to the Boussinesq hypothesis [22,30]. The following equations are the control equations in CFD [38]. 
(1) Continuity equation:

$$
\frac{\partial \rho_{f}}{\partial t}+\nabla \cdot\left(\rho_{f} \vec{v}\right)=S_{m}
$$

where $\rho_{f}$ is the fluid density in $\mathrm{kg} / \mathrm{m}, \vec{v}$ is the velocity vector in $\mathrm{m} / \mathrm{s}$, and $S_{m}$ is the source term for mass generation in $\mathrm{kg} /\left(\mathrm{m}^{3} \cdot \mathrm{s}\right), S_{m}$ is zero. The increase in mass should be equal to the mass flux. Buoyancy force [39] increases as a result of density variation per the assumption that only the effects of the buoyancy term and temperature on fluid density were considered; other effects were ignored [40].

(2) Momentum equation:

$$
\frac{\partial\left(\rho_{f} \vec{v}\right)}{\partial t}+\nabla \cdot\left(\rho_{f} \vec{v} \vec{v}\right)=-\nabla p+\rho_{f} \vec{g}+S_{j}
$$

where $p$ is the static pressure in Pa and $\vec{g}$ is the gravitational force in $\mathrm{N} / \mathrm{m}^{3} . S_{j}$ is the source term for the $j$-th $(x, y$, or $z)$ momentum equation, which is given by

$$
S_{j}=\frac{\mu}{\alpha} v_{j}+C_{2}\left(\frac{1}{2} \rho v\left|v_{j}\right|\right),
$$

where $1 / \alpha$ is the viscous drag coefficient and $C_{2}$ is the inertial resistance coefficient.

The wall treatment in this paper was enhanced to consider the effect of wall roughness on air flow. The wall-enhancement function can be incorporated into the models by establishing a viscous model.

(3) Energy equation:

$$
\frac{\partial}{\partial t}\left(\phi \rho_{f} E_{f}+(1-\phi) \rho_{p} E_{p}\right)+\nabla \cdot\left(\vec{v}\left(\rho_{f} E_{f}+p\right)\right)=\nabla \cdot k_{e f f} \cdot \nabla T-\sum_{i} h_{i} \vec{J}_{i}+S_{f^{\prime}}^{h}
$$

where $\phi$ is the porosity of the medium, $E_{f}$ is the fluid energy in $\mathrm{J} / \mathrm{kg}, E_{p}$ is the product energy in $\mathrm{J} / \mathrm{kg}$, $h_{i}$ is the enthalpy of species $i$ in $\mathrm{J} / \mathrm{kg}, \vec{J}_{i}$ is the diffusion flux in $\mathrm{kg} /\left(\mathrm{m}^{2} \cdot \mathrm{s}\right), S_{f}^{h}$ is the enthalpy source term in $\mathrm{W} / \mathrm{m}^{3}$, and $k_{\text {eff }}$ is the effective thermal conductivity of the porous medium in $\mathrm{W} /(\mathrm{m} \cdot \mathrm{K})$ that can be defined as

$$
k_{e f f}=\phi k_{f}+\left(1-\phi k_{s}\right),
$$

where $k_{f}$ is the fluid-phase thermal conductivity (including turbulence) in $\mathrm{W} /(\mathrm{m} \cdot \mathrm{K})$, and $k_{s}$ is the solid-medium thermal conductivity in $\mathrm{W} /(\mathrm{m} \cdot \mathrm{K})$.

Temperature distribution in cold-storage containers is related to the heat-insulation performance of insulation materials, which includes vacuum insulation boards and polyurethanes. Thermal-insulation performance of storage and temperature-controlled containers can be defined as Equations (6)-(8) [41]:

$$
R_{w}=\frac{1}{\alpha_{1}}+\sum \frac{x_{j}}{\lambda_{j}}+\frac{1}{\alpha_{2}}
$$

where $R_{w}$ is the heat resistance of the storage and temperature-controlled container in $\mathrm{m}^{2} \cdot{ }^{\circ} \mathrm{C} / \mathrm{W}, \lambda_{j}$ is the thermal conductivity of heat-transfer materials in each layer in $\mathrm{W} /(\mathrm{m} \cdot \mathrm{K}), x_{j}$ is the thickness of each material layer in $\mathrm{m}, \alpha_{1}$ is the heat-transfer coefficient of the inner surface of the container in $\mathrm{W} /\left(\mathrm{m}^{2} \cdot \mathrm{K}\right)$, and $\alpha_{2}$ is the heat-transfer coefficient of the outer surface of the container in $\mathrm{W} /\left(\mathrm{m}^{2} \cdot \mathrm{K}\right)$. The container heat transfer coefficients of the inner and outer surfaces are generally calculated by Equations (7) [42]:

$$
\begin{gathered}
\alpha_{i}=1.163 \times\left(4+12 \sqrt{v_{i}}\right) \\
K_{i}=\frac{1}{R_{w}},
\end{gathered}
$$


where $\alpha_{i}$ is the convection heat-transfer coefficient between the wall surface of the container and the air in $\mathrm{W} /\left(\mathrm{m}^{2} \cdot \mathrm{K}\right), v_{i}$ is air-flow velocity inside or outside the container in $\mathrm{m} / \mathrm{s}$, and $K_{i}$ is the heat-transfer coefficient of each surface of the container in $\mathrm{W} /\left(\mathrm{m}^{2} \cdot \mathrm{K}\right)$. The total heat transfer coefficient $K$ of the container is calculated by Formula (9) [42]:

$$
\begin{gathered}
K=\frac{\sum_{i=1}^{S} K_{i} A_{i}}{\sum_{i=1}^{S} A_{i}}, \\
A_{i}=\sqrt{A_{i 1} A_{i 2}} .
\end{gathered}
$$

where $A_{i}$ is the total heat transfer area of container, $A_{i 1}$ and $A_{i 2}$ are the geometric heat transfer area inside and outside the container respectively. Considering the influence of the thermal bridge and sealing on the total heat transfer coefficient, it is necessary to modify the total heat transfer coefficient of the container [43]. The correction factor for this article is 1.15, provided by the container manufacturer. The applicable thermal properties of air were obtained from FLUENT (2003).

Appropriate boundary conditions must be exactly established in this model. The fan outlet was assumed to be the velocity inlet, and the outlet was assumed to be the pressure outlet. Velocity was constant in both inlets as per the boundary conditions for Equations (1) and (2). Velocity in the fan outlet could be stated as $v_{x}=0, v_{y}=v, v_{z}=0$. In this model, $v$ was calculated on the basis of Equation (1). The UDF was used to represent the change of inlet temperature with time under different velocity levels, and data were experimentally obtained (Figure 2). For the produce space, $v$ was affected by the resistance of the produce and its package; this resistance was calculated by using Equation (3). Boundary condition details are shown in Table 2. Viscous resistance and inertial resistance were obtained by measuring the products' ventilation resistance, which was represented by the pressure difference in different velocity, and then it was synthesized to a one variable quadratic equation with no intercept. The hole rate is 0.3 , viscous resistance is 19,441 , and inertial resistance is 0.05891 by measuring and calculating. Due to the impact of forced convection intensity, the inlet temperature of the fan varied with time, the entry boundary cannot be set to the same parameter. Thus, relationship between the air velocity and inlet air temperature, and a user-defined function (UDF) between the two was added into the model. The heat load outside the container was also considered, and its heat transfer coefficient was calculated to $0.13734 \mathrm{~W} / \mathrm{m}^{2} \mathrm{~K}$ by Equation (6) to Equation (10). Average temperature of outside the container within 45 min was tested to represent the wall temperature in the CFD model.

Table 2. Details of boundary conditions.

\begin{tabular}{ccccc}
\hline Name & Inlet & Outlet & Products & Wall \\
\hline Boundary condition & Velocity inlet & Pressure outlet & Porous zone & Convection \\
Velocity $(\mathrm{m} / \mathrm{s})$ & 16 & - & - & - \\
Temperature $(\mathrm{K})$ & UDF & 281.15 & - & 308.15 \\
Pressure $(\mathrm{Pa})$ & - & 0 & - & - \\
Viscous resistance $\left(1 / \mathrm{m}^{2}\right)$ & - & - & 19,441 & - \\
Inertial resistance $(1 / \mathrm{m})$ & - & - & 0.06 & - \\
Heat transfer coefficient $\left(\mathrm{W} / \mathrm{m}^{2} \mathrm{~K}\right)$ & - & - & - & 0.13734 \\
\hline
\end{tabular}




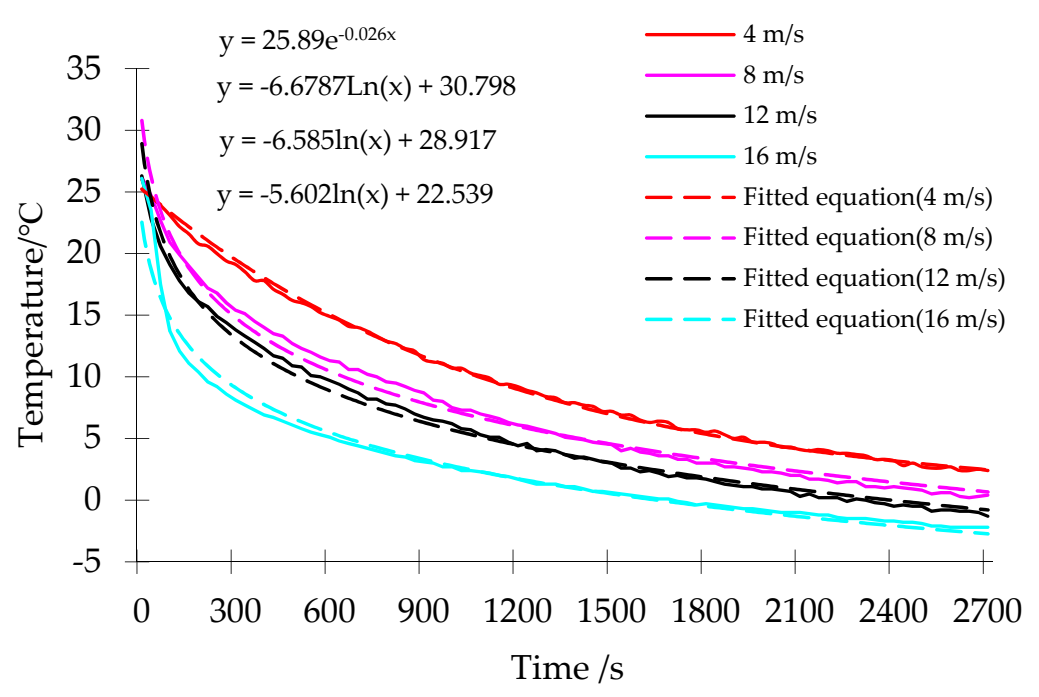

Figure 2. User-defined function (UDF) equation of the inlet temperature over time.

\subsection{Numerical Method}

The length, width, and height of the computational domain, which was developed with CATIA software, were 1.78, 1.17, and $1.49 \mathrm{~m}$, respectively. A hexahedral mesh was used to discretize the model in ICEM-CFD (integrated computer engineering and manufacturing code for computational fluid dynamics) software due to its higher computational accuracy. All of the physical parameters of each element were calculated by the finite-volume method, including velocity, pressure, and temperature. The mesh density of the inlet, outlet, and product surface was improved for greater computational accuracy.

The independence of the generated mesh by ICEM-CFD is very important when simulated in FLUENT. Mesh size is the main reason for direct error accumulation [44,45]. Additionally, large mesh size also significantly slows down calculation efficiency. Therefore, it is necessary to determine proper mesh size, which helps to enhance computation efficiency and calculation accuracy. This part mainly aims to ensure mesh accuracy by monitoring the average velocity of different computational domains and the velocity of the location of the monitor sensor. The number of cells generated by ICEM-CFD ranges from initially 100,000 to approximately 1,000,000 by changing max and min cell size, including local refinement.

Figure 3 shows the schematic of measuring points. Figure 4a shows the average temperature of 15 measuring points and space average temperature in ITCC. Average temperature fluctuated slightly as the number of cells changed from 100,000 to 500,000 . It was also obvious that there was a gentle velocity incline of the monitor sensor in the area from 670,000 to 950,000 , which testified that the number of cells in this area was suitable for simulation in FLUENT. Considering the computational power requirement, a smaller number of cells was selected in this task. A 3D mesh file with 670,000 cells was constructed for this research. The mesh model is shown in Figure $4 \mathrm{~b}$. 


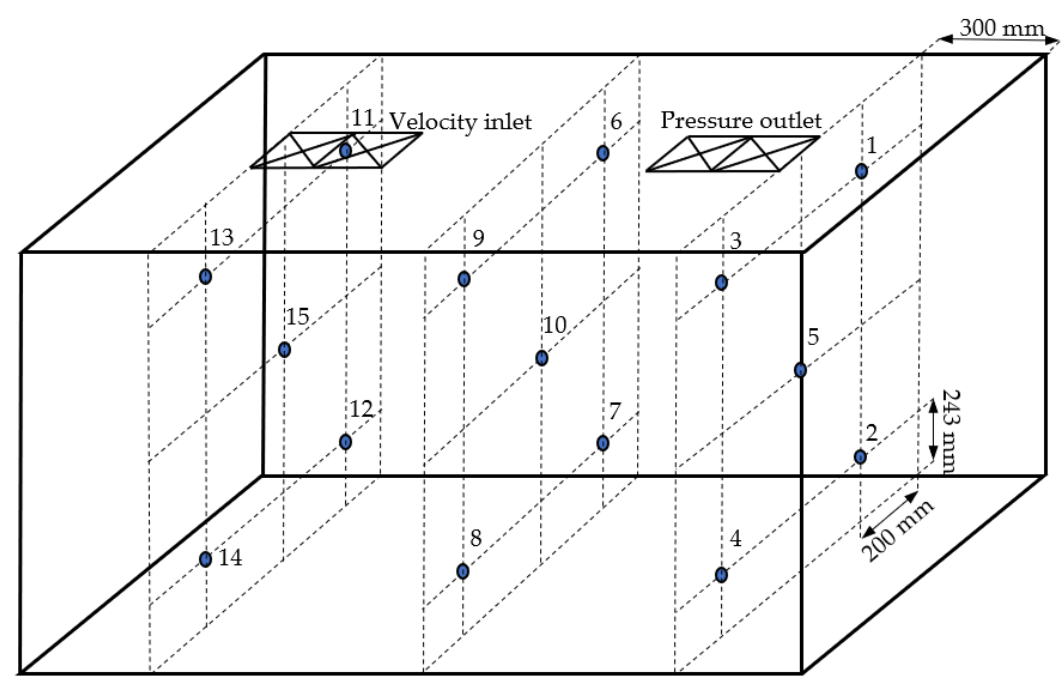

Figure 3. Schematic of measuring points.

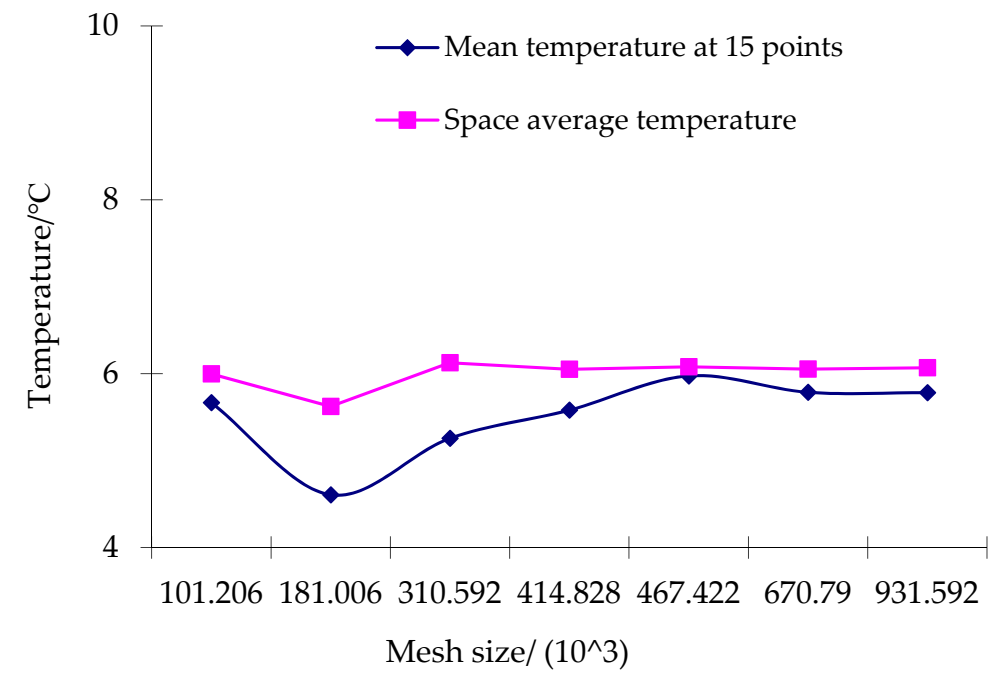

(a)

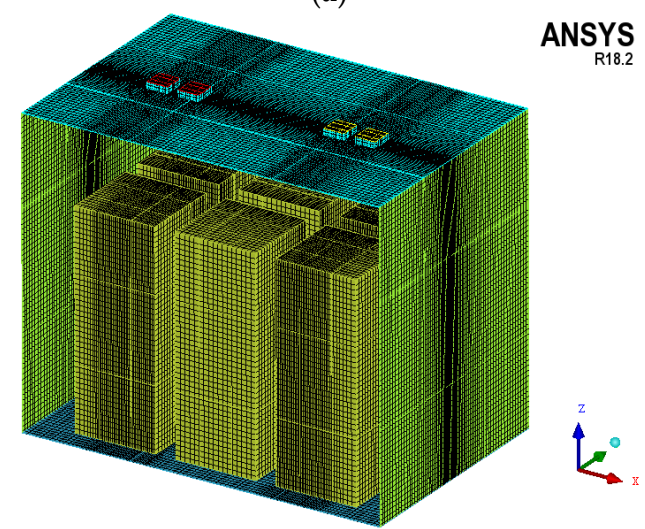

(b)

Figure 4. Results of the mesh-independence study: mesh (a) independence and (b) model.

The Reynolds number (Re) depends on the form of the fluid, and it is a significant variable for simulation, related to selecting a turbulence model. In this study, this variable was calculated using Equation (11) [46]: 


$$
\operatorname{Re}=U L / v,
$$

where $U$ is the characteristic scale of velocity, $\mathrm{m} / \mathrm{s}, L$ is the characteristic scale of length, $\mathrm{m}$, and $v$ is the kinematic viscosity, $\mathrm{m}^{2} / \mathrm{s}$.

Large eddy simulation (LES) is an important means for studying turbulent motion. It has been used in many studies to analyze turbulence under simple geometries and boundary conditions [47-49]. Due to the large computational cost, LES has not been widely applied in engineering. In previous CFD models $[43,49]$, the $k-\varepsilon$ turbulent model was widely used to solve high Re value cases, which were experimentally verified with high accuracy. Therefore, this study used the standard $k-\varepsilon$ model for its lower computational consumption. Turbulence intensity (I) was needed for CFD simulation, which was calculated by Equation (12) [50]:

$$
I=0.16(\operatorname{Re})^{-1 / 8} \text {. }
$$

Computations were performed with an AMD Ryzen 7 PRO 1700 eight-core processor with a 16 GB RAM. The CFD code of this work was Fluent 18.2 with a finite volume approach. A pressure-base model was used for calculation because fluid density had little change. A steady solver was used to initialize the fluid field before using a transient solver, and initialization was done when its convergence of continuity, momentum, and energy reached $10^{-3}, 10^{-3}$, and $10^{-6}$, respectively. Gravitational acceleration was also considered and it was set to be $-9.81 \mathrm{~m} / \mathrm{s}^{2}$. The time step of this case was set as $1 \times 10^{-4} \mathrm{~s}$, with 20 iterations in each time step.

The coefficient of inhomogeneity (COI) was used to evaluate the distribution uniformity of temperature in the container, which could be defined [35] as

$$
S=\sum_{i}^{n}\left|\left(t_{i}-t_{n}\right) / t_{n}\right|
$$

where $S$ is the coefficient of inhomogeneity; $t_{i}$ is the temperature of $\mathrm{i}_{\text {th }}$ sensor, ${ }^{\circ} \mathrm{C}$; and $t_{n}$ is the average temperature of $\mathrm{n}$ sensors, ${ }^{\circ} \mathrm{C}$.

\subsection{Physical Model}

Four groups of air velocity and four groups of fan locations were selected for numerical analysis to optimize temperature distribution in the container. Air velocity was $4,8,12$, and $16 \mathrm{~m} / \mathrm{s}$, respectively. The specific locations of the fan are shown in Figure 5. In all cases, the same parameters, solution method, initial conditions, and boundary conditions were used.

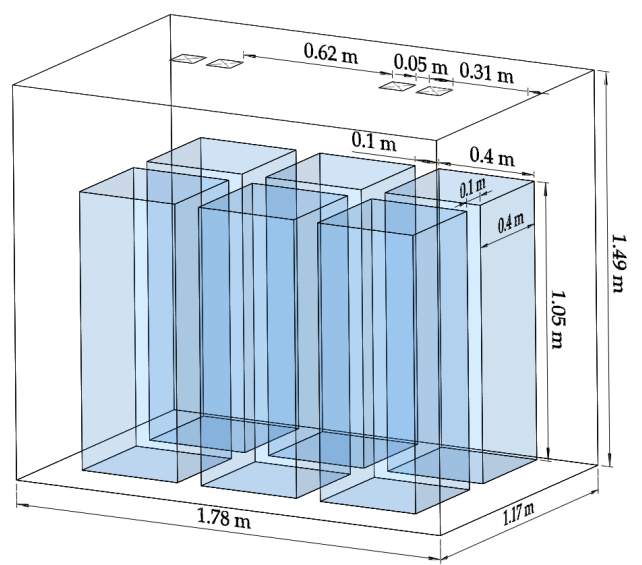

(a)

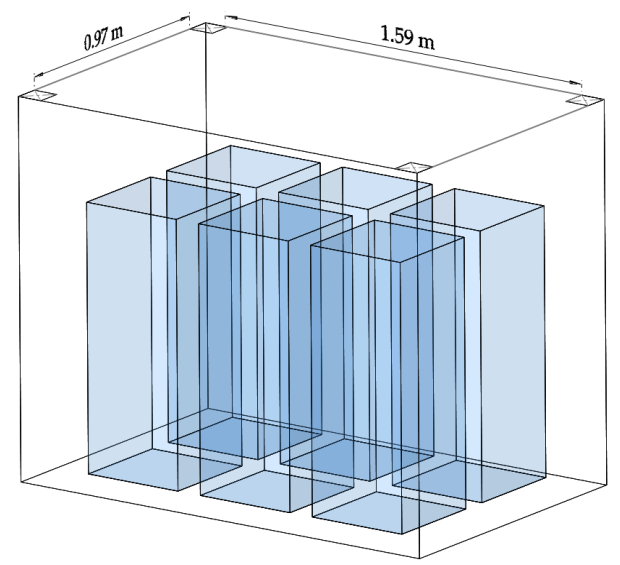

(b)

Figure 5. Cont. 


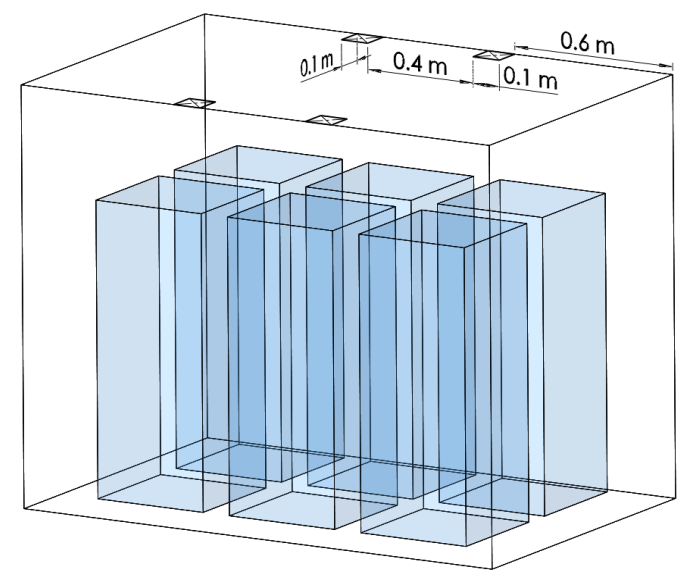

(c)

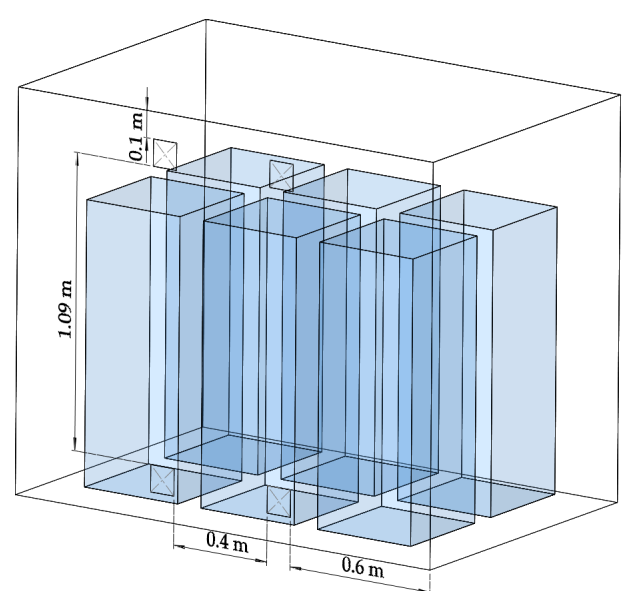

(d)

Figure 5. Specification of different fan locations: (a) L0; (b) L1; (c) L2; and (d) L3.

\subsection{Experimental Research}

Experiments were carried out in the ITCC (1:1 scale as the container) with cold-storage and temperature-control transportation. These experiments served to verify the accuracy of the simulation models. Temperature and air velocity were recorded by fifteen thermocouples and fifteen hot wire anemometers respectively. On the basis of the results of a previous analysis, the locations of these sensors were determined and are shown in Figure 3. Thermocouples (CHT-D version) with a measuring range of $-20-80{ }^{\circ} \mathrm{C}$ and accuracy of $\pm 0.3^{\circ} \mathrm{C}$ were used. Hot wire anemometers (CHWVN WD4150) with a measuring velocity range of $0-30 \mathrm{~m} / \mathrm{s}$ and accuracy $0.02 \%$ of the read value and resolution of $0.01 \mathrm{~m} / \mathrm{s}$ were used.

The navel oranges used in the experiment were purchased from a Jiangnan fruit wholesale market in Guangzhou and transported to the College of Engineering of South China Agricultural University by refrigerated transportation. In order to ensure the quality of the navel oranges, they were carefully graded, and damaged and inferior-quality samples were eliminated. Before the experiments, the cold-storage plate was fully frozen in $-20^{\circ} \mathrm{C}$ cold storage, and the oranges were precooled to $8{ }^{\circ} \mathrm{C}$; then, the oranges and cold-storage plate were quickly moved to the cold-storage area to start the temperature-control experiment. The temperature-control interval was set to $2-8{ }^{\circ} \mathrm{C}$. The sensors were connected to a data-recording instrument with a data-recording interval of $10 \mathrm{~s}$.

\section{Results}

\subsection{Model Verification}

Figure 6a shows the difference of experimental air velocity and simulation air velocity, where the maximal and minimal air velocity difference between the experiment and simulated air velocity was 0.59 and $0.02 \mathrm{~m} / \mathrm{s}$, respectively, and the average air velocity difference was $0.11 \mathrm{~m} / \mathrm{s}$. The experimental air velocity ranged from 0.28 to $6.86 \mathrm{~m} / \mathrm{s}$ while simulation air velocity ranged from 0.18 to $7.0 \mathrm{~m} / \mathrm{s}$. Temperature data of 15 sensors were obtained when the monitor sensor had reached $2{ }^{\circ} \mathrm{C}$ after $45 \mathrm{~min}$. Figure $6 \mathrm{~b}$ shows the difference of the experimental temperature and simulation temperature. Figure $6 \mathrm{~b}$ shows that the maximal and minimal temperature difference between the experiment and simulated temperatures was 2.1 and $0.12{ }^{\circ} \mathrm{C}$, respectively, and the average temperature difference was $0.9^{\circ} \mathrm{C}$. The experimental temperature ranged from 0.3 to $5.2^{\circ} \mathrm{C}$ while the simulation temperature ranged from 0.9 to $5.3{ }^{\circ} \mathrm{C}$, but the average experimental temperature was higher than the simulation temperature, which was 4.9 and $4.4{ }^{\circ} \mathrm{C}$, respectively. It might be caused by ignoring the heat leakage of the container. Considering the various parameters of the control simulation and experiment, this difference was 
acceptable. Such results of the verification experiments proved that the simulation results had a certain degree of accuracy that is beneficial to the ITCC design and optimization.

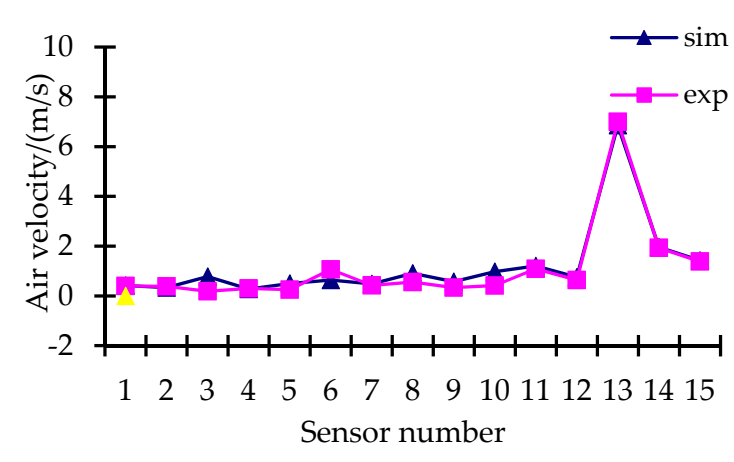

(a)

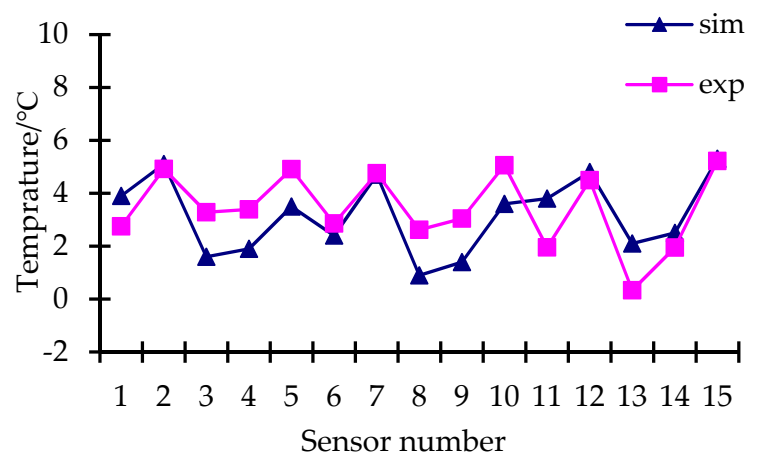

(b)

Figure 6. Comparison of simulation and experiment: (a) temperature and (b) air velocity.

\subsection{Air-Flow and Temperature Distribution}

Air velocity is a significant factor that affects produce quality, especially weight loss. Figure 7 shows air-velocity distribution and air streamlines in the ITCC. As can be seen from Figure 7a, high velocity on the produce surface was below the fan outlet and the bottom of the produce. High velocity below the fan outlet might have been caused by direct blowing. Air from the fan outlet rushed to the floor of the container and spread along the bottom guide rail to other areas of the bottom, resulting in higher velocity at the produce bottom. According to the study of Ambaw et al. [51] on the velocity distribution of apple refrigerators, air flow blown out by a front cooling device also had higher local velocity when reaching the opposite wall, which is consistent with the analysis results in this paper. Low velocity could be seen near the outlets, far from the door. Figure $7 \mathrm{~b}$ shows the air streamlines, which perfectly explain the reason for this velocity field. Uniform air-flow distribution could effectively improve heat-exchange efficiency in the container and reduce the quality attenuation of goods due to large local air-flow velocity, and it was more conducive to ensuring the quality uniformity of the transported goods.

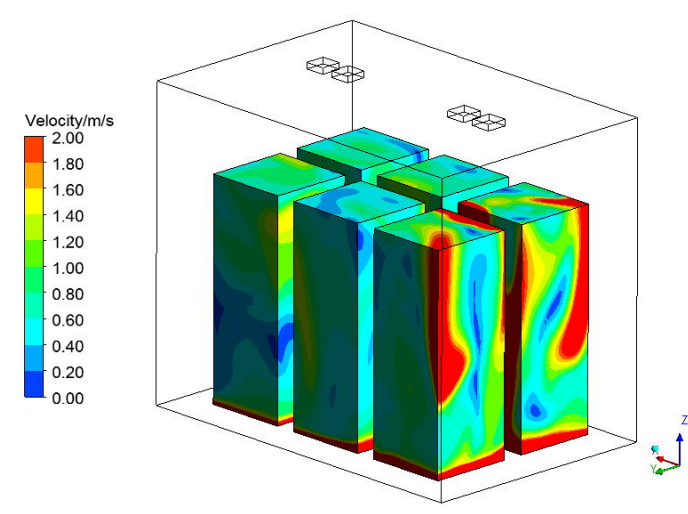

(a)

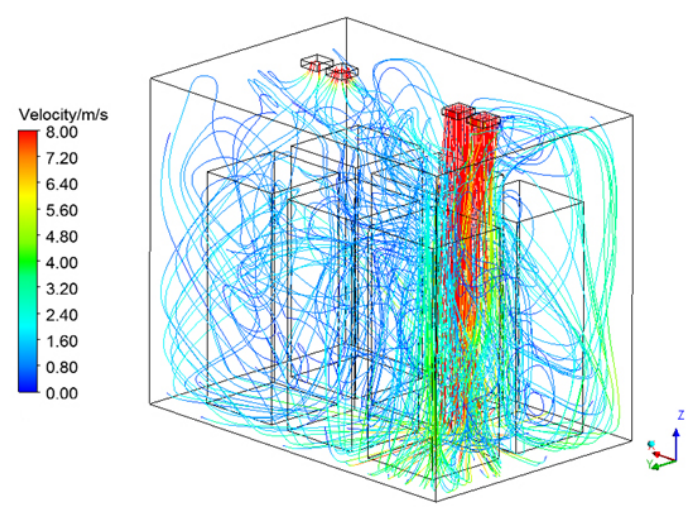

(b)

Figure 7. ITCC velocity distribution. (a) Velocity distribution on the produce surface and (b) container streamlines.

Temperature is another significant factor that affects product quality. Figure 8 shows the temperature distribution in the whole container. The temperature partition in the container is obvious, and there was great temperature difference in the container. Temperature in the area near the fan outlet was lower, while temperature in the area away from the fan outlet was higher, especially far below the 
fan outlet. Since the cold air could not reach these parts, it resulted in a high temperature region in the products. There were two main reasons for this, one was that these parts were an airflow blind area, the other was that the products blocked the arrival of the cold air. Temperature on the product surface reached $6.18^{\circ} \mathrm{C}$, while it was $-1.59^{\circ} \mathrm{C}$ near the fan outlet (Figure 8a). Maximal temperature difference on the product surface reached $7.77^{\circ} \mathrm{C}$ (Figure 8a), and maximal temperature difference in the rest of the space was $6.31{ }^{\circ} \mathrm{C}$. Uneven temperature distribution led to the fruit freezing in some areas, while the high temperature in some areas may have accelerated the rot of the fruit in those areas. Therefore, it is necessary to optimize temperature distribution in the future.

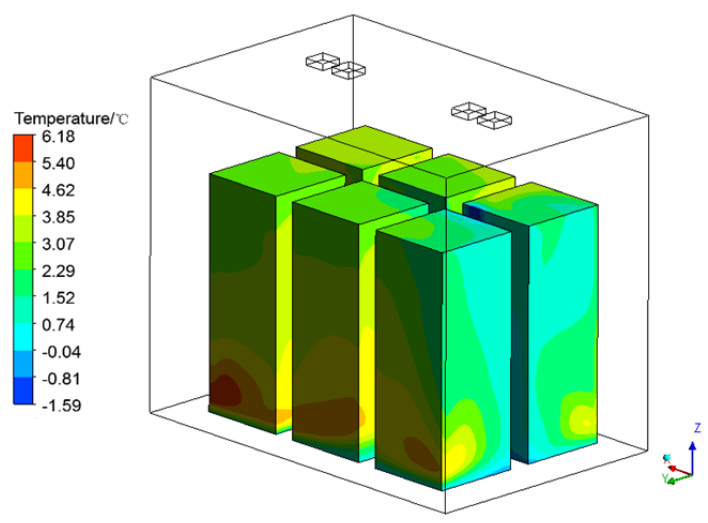

(a)

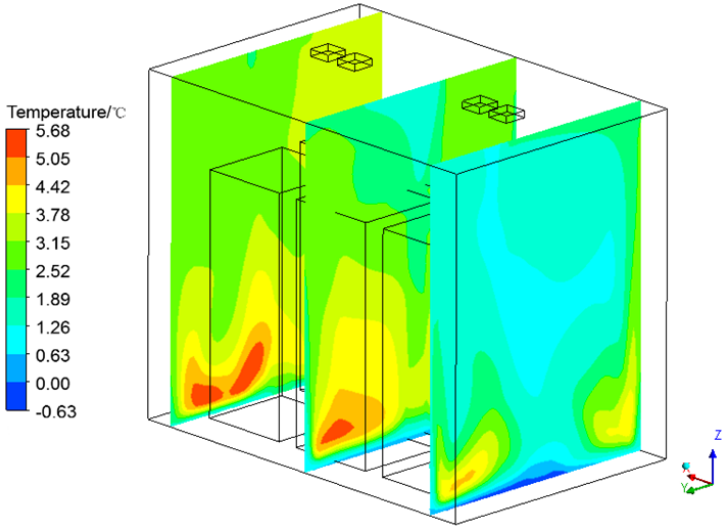

(b)

Figure 8. ITCC temperature distribution (a) on the produce surface and (b) in the container.

\subsection{Inlet-Velocity Influence}

Four velocity levels were selected to study its influence on cooling time and temperature distribution; results are shown in Figures 9 and 10. Figure 9 shows that the high-temperature area gradually decreased as velocity increased, while the low-temperature area gradually increased. Table 3 shows the analysis results of the different parameters, including the average temperature (AT), standard deviation (STEDV), and the coefficient of inhomogeneity (COI). As can be seen from Table 3, AT decreased as velocity increased, which led us to conclude that higher velocity brought more cold air into the container, and resulted in a lower temperature distribution inside it. However, the COI appeared to increase as velocity increased, which indicates bad temperature uniformity in the container. STEDV fluctuated within the range of 1.44-1.63, which also showed that $16 \mathrm{~m} / \mathrm{s}$ is more beneficial for temperature in the container.

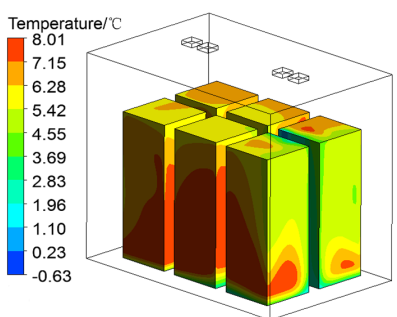

(a)

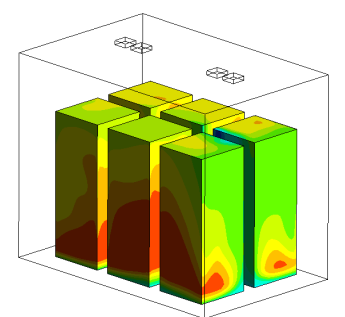

(b)

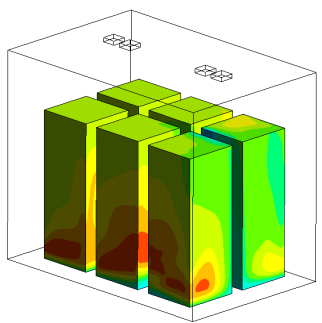

(c)

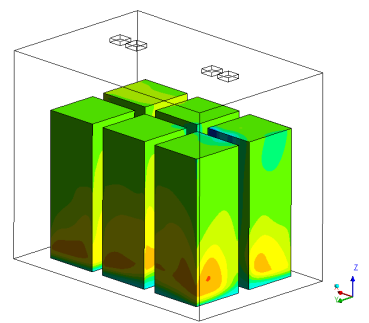

(d)

Figure 9. Temperature distribution with different velocity levels: (a) $4 \mathrm{~m} / \mathrm{s}$; (b) $8 \mathrm{~m} / \mathrm{s}$; (c) $12 \mathrm{~m} / \mathrm{s}$; and (d) $16 \mathrm{~m} / \mathrm{s}$. 
Table 3. Analysis results of different parameters.

\begin{tabular}{ccccc}
\hline Items & $\mathbf{4 ~ \mathbf { ~ } / \mathbf { s }}$ & $\mathbf{8 ~ \mathbf { ~ m } / \mathbf { s }}$ & $\mathbf{1 2 ~ \mathbf { ~ } / \mathbf { s }}$ & $\mathbf{1 6 ~ \mathbf { ~ } / \mathbf { s }}$ \\
\hline Average temperature (AT; $\left.{ }^{\circ} \mathrm{C}\right)$ & 6.29 & 5.27 & 4.25 & 3.95 \\
Standard deviation (STEDV) & 1.63 & 1.89 & 1.86 & 1.44 \\
Coefficient of inhomogeneity (COI) & 2.74 & 3.96 & 4.32 & 5.35 \\
\hline
\end{tabular}

Figure 10 shows the cooling time with different velocity levels, which had an accelerated cooling rate by increasing air circulation. These results indicated that the cooling rate improved with velocity increasing; the cooling range was between 2.05 and $2.95^{\circ} \mathrm{C}$ from 5 to $45 \mathrm{~min}$. The cooling capacity release rate of the storage module was affected by forced convection and thermal conductivity [52], and the cooling capacity released in a certain period was limited. When air velocity was low, the cooling capacity taken away from the storage area was lower than the cooling capacity released by the storage module, resulting in a high outlet temperature of the fan, thus affecting the cooling rate in the cargo area. With the increase in velocity, the release rate of the cooling capacity of the storage module increased, but the amount of cooling capacity taken away from the storage area could only infinitely approach the amount of cooling capacity released by the storage module. After reaching an equilibrium point, the outlet temperature of the fan was basically constant. When velocity was $4 \mathrm{~m} / \mathrm{s}$ at $45 \mathrm{~min}$, temperature was $5.27^{\circ} \mathrm{C}$, which was more than $1{ }^{\circ} \mathrm{C}$ higher than the three other velocity levels, indicating that the amount of cold released from the storage area was not brought into the product area. The cooling trend of 12 and $16 \mathrm{~m} / \mathrm{s}$ velocity indicated that the temperature difference in the cargo area in the first $30 \mathrm{~min}$ was significantly higher than that after $30 \mathrm{~min}$, indicating that, when air velocity was $12 \mathrm{~m} / \mathrm{s}$, the cooling rate of the storage module and the cooling rate brought into the product area by the fan basically tended to be stable. In the forced air-cooling system, energy consumption mainly depends on the power needed to generate the air flow passing through the stack (i.e., fan power) and the time needed to maintain the air flow (i.e., cooling time). For a cooling-storage system, the influence of ventilation velocity on the cooling-release rate of the storage module needs to be considered. When considering the energy consumption of the fan, the cooling rate of the cooling module, and the temperature-field distribution in the product area, we found the $12 \mathrm{~m} / \mathrm{s}$ velocity level to be better than the others.

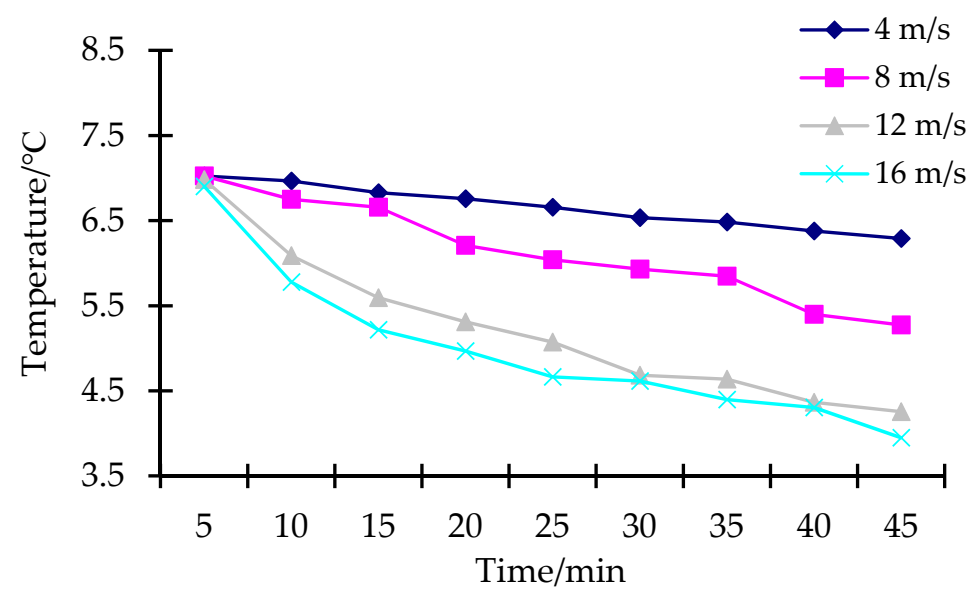

Figure 10. Cooling time with different velocity levels.

\subsection{Fan-Location Influence}

Figure 11 shows the temperature distribution on the product surface with different locations of the ventilation fan. The size of the high- and low-temperature areas changed little as the fan location changed, and the product temperature ranged from -2 to $8^{\circ} \mathrm{C}$. Table 4 also shows that its AT ranged from 4.62 to $4.95^{\circ} \mathrm{C}$, which showed little difference. However, its temperature STEDV and COI had a 
large difference when the fan location changed, ranging from 0.87 to 1.86 and 2.10 to 4.32 , respectively. STEDV and COI results indicated that the temperature distribution in the container was more uniform when the fan was located at the top four corners of the container. The trajectory of the air is longer when the fan was located at the top four corners of the container, so the cold air would exchange sufficient heat with the products, and resulted in more uniform temperature distribution in the container.

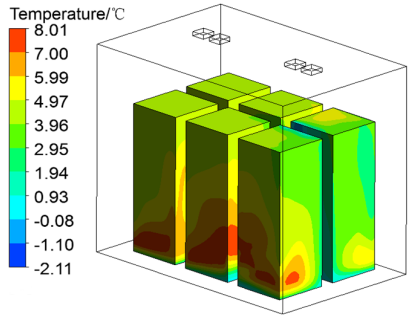

(a)

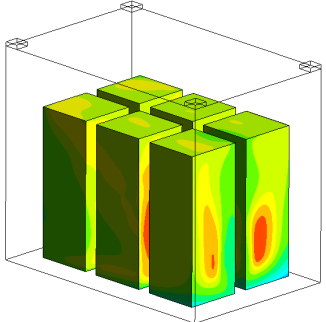

(b)

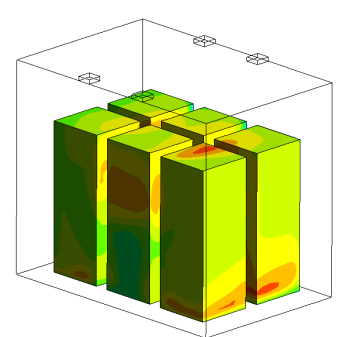

(c)

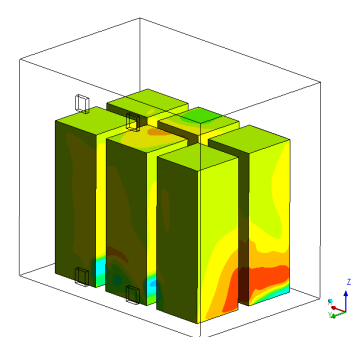

(d)

Figure 11. Temperature distribution with different fan locations: (a) L0; (b) L1; (c) L2; and (d) L3.

Table 4. Analysis results of different parameters.

\begin{tabular}{ccccc}
\hline Items & L0 & L1 & L2 & L3 \\
\hline Average temperature (AT; ${ }^{\circ}$ C) & 4.25 & 4.13 & 4.62 & 4.95 \\
Standard deviation (STEDV) & 1.86 & 0.87 & 1.51 & 1.49 \\
Coefficient of inhomogeneity (COI) $^{2}$ & 4.32 & 2.10 & 3.3 & 2.68 \\
\hline
\end{tabular}

\section{Conclusions}

This paper studied the uniformity of temperature distribution in a novel insulated temperature-controlled container (ITCC). A CFD method was adopted to simulate the flow field and heat-transfer mechanism, which provided more insightful understanding of the heat transfer in the container. Mesh size was studied for better precision before simulation, and experiment validation showed that the simulation values were in good agreement with the experiment values. Four ventilation-velocity levels and four locations of the ventilation fan were selected to compare their temperature distribution in the container. The following conclusions were drawn.

(1) Ventilation velocity had great influence on the cooling time. Cooling rate improved as velocity increased, and temperature at $45 \mathrm{~min}$ was lowest when velocity was $16 \mathrm{~m} / \mathrm{s}$.

(2) The coefficient of inhomogeneity increased when velocity increased, which indicated bad temperature uniformity. However, considering the energy consumption of the fan, the cooling rate of the cooling module, and the temperature-field distribution in the product area, $12 \mathrm{~m} / \mathrm{s}$ velocity was better than the others.

(3) Temperature standard deviation in the container and coefficient of inhomogeneity were the lowest when the fans were located at the top four corners of the container, namely, 0.87 and 2.1, respectively. Compared with before, the average temperature in the box was decreased by $0.12{ }^{\circ} \mathrm{C}$, and the coefficient of inhomogeneity was decreased by more than twofold.

The simulation and experiment results showed good agreement; thus, the present study can provide a reference for research on parameter optimization of insulated temperature-controlled containers. However, the results of this study cannot be generalized to any space conditions because they are relevant to the specific conditions of the experiment.

Author Contributions: Conceptualization and methodology, B.L. and X.W.; software, Y.C.; validation, Y.C. and H.S.; formal analysis, J.G.; writing-original-draft preparation, B.L.; writing-review and editing, all authors; visualization, B.L.; supervision, H.L., J.X. and E.L. All authors have read and agreed to the published version of the manuscript. 
Funding: This research was funded by the National Natural Science Foundation of China, grant nos. 31971806 and 31901736; the Natural Science Foundation of Guangdong Province, grant no. 2020A1515010967; the Guangdong Provincial Agricultural Technology Innovation and Promotion Project in 2019, grant no. 2019KJ101; the Research and Development and Innovation Team of Common Key Technologies for Agricultural-Product Preservation Logistics, grant no. 2019KJ145; and the Guangdong Province Key Field R\&D Program, grant no. 2019 B020225001.

Acknowledgments: The authors are grateful for the support of the South China Agricultural University and Guangzhou Hicool Technology Co., Ltd. The authors also thank the anonymous reviewers for their critical comments and suggestions to improve the manuscript.

Conflicts of Interest: The authors declare no conflict of interest.

\section{References}

1. Liu, M.; Saman, W.; Bruno, F. Computer simulation with TRNSYS for a mobile refrigeration system incorporating a phase change thermal storage unit. Appl. Energy 2014, 132, 226-235. [CrossRef]

2. Mercier, S.; Villeneuve, S.; Mondor, M.; Uysal, I. Time-Temperature Management along the Food Cold Chain: A Review of Recent Developments. Compr. Rev. Food Sci. Food Saf. 2017, 16, 647-667. [CrossRef]

3. Oury, A.; Namy, P.; Youbi-Idrisi, M. Aero-thermal Simulation of a Refrigerated Truck under Open/Closed-Door Cycles. In Proceedings of the 2015 COMSOL Conference, Grenoble, France, 14 November 2015.

4. Liu, M.; Saman, W.; Bruno, F. Development of a novel refrigeration system for refrigerated trucks incorporating phase change material. Appl. Energy 2012, 92, 336-342. [CrossRef]

5. Ahmed, M.; Meade, O.; Medina, M.A. Reducing heat transfer across the insulated walls of refrigerated truck trailers by the application of phase change materials. Energy Convers. Manag. 2010, 51, 383-392. [CrossRef]

6. Pielichowska, K.; Pielichowski, K. Phase change materials for thermal energy storage. Prog. Mater. Sci. 2014, 65, 67-123. [CrossRef]

7. Zhou, D.; Zhao, C.Y.; Tian, Y. Review on thermal energy storage with phase change materials (PCMs) in building applications. Appl. Energy 2012, 92, 593-605. [CrossRef]

8. Oró, E.; Miró, L.; Farid, M.M.; Cabeza, L.F. Thermal analysis of a low temperature storage unit using phase change materials without refrigeration system. Int. J. Refrig. 2012, 35, 1709-1714. [CrossRef]

9. Liu, L.; Su, D.; Tang, Y.; Fang, G. Thermal conductivity enhancement of phase change materials for thermal energy storage: A review. Renew. Sustain. Energy Rev. 2016, 62, 305-317. [CrossRef]

10. Fioretti, R.; Principi, P.; Copertaro, B. A refrierated container envelope with a PCM (Phase Change Material) layer: Experimental and theoretical investigation in a representative town in Central Italy. Energy Convers. Manag. 2016, 122, 131-141. [CrossRef]

11. Oró, E.; de Gracia, A.; Cabeza, L.F. Active phase change material package for thermal protection of ice cream containers. Int. J. Refrig. 2013, 36, 102-109. [CrossRef]

12. Wang, C.; He, Z.; Li, H.; Wennerstern, R.; Sun, Q. Evaluation on Performance of a Phase Change Material Based Cold Storage House. Energy Procedia 2017, 105, 3947-3952. [CrossRef]

13. Yusufoglu, Y.; Apaydin, T.; Yilmaz, S.; Paksoy, H.O. Improving performance of household refrigerators by incorporating phase change materials. Int. J. Refrig. 2015, 57, 173-185. [CrossRef]

14. Huang, L.; Piontek, U. Improving Performance of Cold-Chain Insulated Container with Phase Change Material: An Experimental Investigation. Appl. Sci. 2017, 7, 1288. [CrossRef]

15. Gin, B.; Farid, M.M. The use of PCM panels to improve storage condition of frozen food. J. Food Eng. 2010, 100, 372-376. [CrossRef]

16. Liu, G.; Wu, J.; Alan, F.; Xie, R.; Tang, H.; Zou, Y.; Qu, R. Design and no-load performance test of GU-PCM2 temperature controlled phase change storage refrigerator. Trans. Chin. Soc. Agric. Eng. 2019, 35, 288-295.

17. Xu, X.F.; Zhang, X.L.; Munyalo, J.M. Simulation Study on Temperature Field and Cold Plate Melting of Cold Storage Refrigerator Car. Energy Procedia 2017, 142, 3394-3400.

18. Zhang, Z.; Guo, Y.G.; Tian, J.J.; Li, M. Numerical simulation and experiment of temperature field distribution in box of cold plate refrigerated truck. Trans. Chin. Soc. Agric. Eng. 2013, 29, 18-24.

19. Zou, Q.; Opara, L.U.; McKibbin, R. A CFD modeling system for airflow and heat transfer in ventilated packaging for fresh foods: I. Initial analysis and development of mathematical models. J. Food Eng. 2006, 77, 1037-1047. [CrossRef]

20. Jiang, T.; Xu, N.; Luo, B.; Deng, L.; Wang, S.; Gao, Q.; Zhang, Y. Analysis of an internal structure for refrigerated container: Improving distribution of cooling capacity. Int. J. Refrig. 2020, 113, 228-238. [CrossRef] 
21. Jedermann, R.; Geyer, M.; Praeger, U.; Lang, W. Sea transport of bananas in containers-Parameter identification for a temperature model. J. Food Eng. 2013, 115, 330-338. [CrossRef]

22. Delele, M.A.; Ngcobo, M.E.K.; Getahun, S.T.; Chen, L.; Mellmann, J.; Opara, U.L. Studying airflow and heat transfer characteristics of a horticultural produce packaging system using a 3-D CFD model. Part II: Effect of package design. Postharvest Biol. Technol. 2013, 86, 546-555. [CrossRef]

23. Zhang, Z.; Li, L.; Tian, J.; Guo, Y.; Li, Y. Effects of refrigerated truck temperature field uniformity on preservation of vegetables. Trans. Chin. Soc. Agric. Eng. 2014, 30, 309-316.

24. Defraeye, T.; Nicolai, B.; Kirkman, W.; Moore, S.; Niekerk, S.V.; Verboven, P.; Cronjé, P. Integral performance evaluation of the fresh-produce cold chain: A case study for ambient loading of citrus in refrigerated containers. Postharvest Biol. Technol. 2016, 112,1-13. [CrossRef]

25. Trias, F.X.; Oliet, C.; Rigola, J.; Pérez-Segarra, C.D. A simple optimization approach for the insulation thickness distribution in household refrigerators. Int. J. Refrig. 2018, 93, 169-175. [CrossRef]

26. Thiessen, S.; Knabben, F.T.; Melo, C.; Gonçalves, J.M. A study on the effectiveness of applying vacuum insulation panels in domestic refrigerators. Int. J. Refrig. 2018, 96, 10-16. [CrossRef]

27. Hammond, E.C.; Evans, J.A. Application of Vacuum Insulation Panels in the cold chain-Analysis of viability. Int. J. Refrig. 2014, 47, 58-65. [CrossRef]

28. Smale, N.J.; Moureh, J.; Cortella, G. A review of numerical models of airflow in refrigerated food applications. Int. J. Refrig. 2006, 29, 911-930. [CrossRef]

29. Sajadiye, S.M.; Zolfaghari, M. Simulation of in-line versus staggered arrays of vented pallet boxes for assessing cooling performance of orange in cool storage. Appl. Therm. Eng. 2017, 115, 337-349. [CrossRef]

30. Moureh, J.; Flick, D. Airflow pattern and temperature distribution in a typical refrigerated truck configuration loaded with pallets. Int. J. Refrig. 2004, 27, 464-474. [CrossRef]

31. Kayansayan, N.; Alptekin, E.; Ezan, M.A. Thermal analysis of airflow inside a refrigerated container. Int. J. Refrig. 2017, 84, 76-91. [CrossRef]

32. Jara, P.B.T.; Rivera, J.J.A.; Merino, C.E.B.; Silva, E.V.; Farfán, G.A. Thermal behavior of a refrigerated vehicle: Process simulation. Int. J. Refrig. 2019, 100, 124-130. [CrossRef]

33. Han, J.; Zhu, W.; Ji, Z. Comparison of veracity and application of different CFD turbulence models for refrigerated transport. Artif. Intell. Agric. 2019, 3, 11-17.

34. Yang, T.; Wang, C.; Sun, Q.; Wennersten, R. Study on the application of latent heat cold storage in a refrigerated warehouse. Energy Procedia 2017, 142, 3546-3552. [CrossRef]

35. Xie, R.; Tang, H.; Tao, W.; Liu, G.; Liu, J.; Wu, J. Optimization of cold-plate location in refrigerated vehicles based on simulation and test of no-load temperature field. Trans. Chin. Soc. Agric. Eng. 2017, 33, 290-298.

36. Guo, J.; Fang, S.; Zeng, Z.; Lu, H.; Lü, E. Numerical simulation and experimental verification on humidity field for pipeline humidifying device. Trans. Chin. Soc. Agric. Eng. 2015, 31, 57-64.

37. Cheng, W.; Yuan, X. Numerical analysis of a novel household refrigerator with shape-stabilized PCM (phase change material) heat storage condensers. Energy 2013, 59, 265-276. [CrossRef]

38. Chourasia, M.K.; Goswami, T.K. Simulation of Effect of Stack Dimensions and Stacking Arrangement on Cool-down Characteristics of Potato in a Cold Store by Computational Fluid Dynamics. Bioprocess Eng. 2007, 96, 503-515. [CrossRef]

39. Clarke, H.; Martinez-Herasme, A.; Crookes, R.; Wen, D.S. Experimental study of jet structure and pressurisation upon liquid nitrogen injection into water. Int. J. Multiph. Flow 2010, 36, 940-949. [CrossRef]

40. Ho, S.H.; Rosario, L.; Rahman, M.M. Numerical simulation of temperature and velocity in a refrigerated warehouse. Int. J. Refrig. 2010, 33, 1015-1025. [CrossRef]

41. Choi, S.; Burgess, G. Practical mathematical model to predict the performance of insulating packages. Packag. Technol. Sci. 2007, 20, 369-380. [CrossRef]

42. Fang, G.Y.; LI, H. Automobile Air Conditioning Technology, 1st ed.; China Machine Press: Beijing, China, 2002; pp. 88-89.

43. Wang, D.B.; Song, Q.W. Optimum design insulated body of refrigerated van. J. Jiangsu Ins. Technol. 1993, 14, 13-18.

44. Guo, J.; Lü, E.; Lu, H.; Wang, Y.; Zhao, J. Numerical Simulation of Gas Exchange in Fresh-keeping Transportation Containers with a Controlled Atmosphere. Food Sci. Technol. Res. 2016, 22, 429-441. [CrossRef]

45. Hahn, M.; Drikakis, D. Large-eddy simulation of compressible turbulence using high-resolution methods. Int. J. Numer. Methods Fluids 2005, 47, 971-977. [CrossRef] 
46. Tsoutsanis, P.; Antoniadis, A.F.; Drikakis, D. WENO schemes on arbitrary unstructured meshes for laminar, transitional and turbulent flow. J. Comput. Phys. 2014, 256, 254-276. [CrossRef]

47. Thornber, B.J.R.; Drikakis, D. Numerical dissipation of upwind schemes in low Mach flow. Int. J. Numer. Methods Fluids 2008, 56, 1535-1541. [CrossRef]

48. Söylemez, E.; Alpman, E.; Onat, A.; Yükselentürk, Y.; Hartomacioğlu, S. Numerical (CFD) and experimental analysis of hybrid household refrigerator including thermoelectric and vapour compression cooling systems. Int. J. Refrig. 2019, 99, 300-315. [CrossRef]

49. Aslam Bhutta, M.M.; Hayat, N.; Bashir, M.H.; Khan, A.R.; Ahmad, K.N.; Khan, S. CFD applications in various heat exchangers design: A review. Appl. Therm. Eng. 2012, 32, 1-12. [CrossRef]

50. Jaramillo, J.E.; Pérez-Segarra, C.; Oliva, A.; Claramunt, K. Analysis of different RANS models applied to turbulent forced convection. Int. J. Heat Mass Transfer. 2007, 50, 3749-3766. [CrossRef]

51. Ambaw, A.; Bessemans, N.; Gruyters, W.; Gwanpua, S.G.; Schenk, A.; De Roeck, A.; Delele, M.A.; Verboven, P.; Nicolai, B.M. Analysis of the spatiotemporal temperature fluctuations inside an apple cool store in response to energy use concerns. Int. J. Refrig. 2016, 66, 156-168. [CrossRef]

52. Alzuwaid, F.A.; Ge, Y.T.; Tassou, S.A.; Sun, J. The novel use of phase change materials in an open type refrigerated display cabinet: A theoretical investigation. Appl. Energy 2016, 180, 76-85. [CrossRef]

(C) 2020 by the authors. Licensee MDPI, Basel, Switzerland. This article is an open access article distributed under the terms and conditions of the Creative Commons Attribution (CC BY) license (http://creativecommons.org/licenses/by/4.0/). 